\title{
Echocardiographic post-neonatal progress of preterm neonates with patent ductus arteriosus
}

\author{
Jorge Yussef Afiune, ${ }^{1}$ Julio $^{\text {M. Singer, }}{ }^{2}$ Cléa Rodrigues Leone ${ }^{3}$
}

\begin{abstract}
Objective: To identify clinical and echocardiography predictors of the spontaneous closure of patent ductus arteriosus in preterm neonates.

Methods: Sixty-one consecutive preterm neonates (gestational age $30 \pm 2$ weeks, birth weight $1.2 \pm 0.2 \mathrm{~kg}$ ) were evaluated by echocardiogram on their third day of life and those with patent ductus arteriosus were selected for a prospective cohort. Echocardiography was repeated weekly until they reached term. Based on their progress, the sample population was divided into two groups, depending on whether spontaneous closure of patent ductus arteriosus took place (Group A) or not (Group B). The prevalence of clinical signs of patent ductus arteriosus and echocardiography findings at baseline were compared between the groups.

Results: Patent ductus arteriosus was found in 21 neonates (34\%). Spontaneuous closure was observed during follow-up of seven patients (Group A, $33 \%$ of those with patent ductus arteriosus), in contrast with the remaining 14 patients (Group B, 67\%). Clinical signs of patent ductus arteriosus were present in $14 \%$ of the patients in Group A, compared with $71 \%$ in group $B(p=0.01)$. At baseline, Group $B$ had a larger ductus diameter in relation to Group A $(2.6 \pm 0.6 \mathrm{~mm}$ vs. $1.4 \pm 0.6 \mathrm{~mm} ; \mathrm{p}=0.003)$. The area under the ROC curve in relation to ductus diameter was 0.93 $(p=0.003)$ and $100 \%$ sensitivity for identifying cases without spontaneous closure was obtained at the cutoff point of $1.7 \mathrm{~mm}$, while $100 \%$ specificity was observed taking $2.2 \mathrm{~mm}$ as the cutoff.
\end{abstract}

Conclusions: In preterm neonates, a patent ductus arteriosus greater than $2.2 \mathrm{~mm}$ on the third day of life predicts no spontaneous closure and suggests a need for early treatment, especially when associated with clinical signs.

J Pediatr (Rio J). 2005;81(6):454-60: Preterm neonates, echocardiography, patent ductus arteriosus.

\section{Introduction}

Studies employing Doppler echocardiogram and color flow mapping have indicated that functional closure of the ductus arteriosus in full term infants takes place in practically all newborns at around 72 hours of life. ${ }^{1}$ In preterm newborns (PT-NB), the ductus arteriosus closes

1. Supervisor physician, Division of Pediatric Cardiology, Instituto do Coração do Distrito Federal (InCor-DF), Brasília, DF, Brazil.

2. Professor, Department of Statistics, Universidade de São Paulo (USP), São Paulo, SP, Brazil.

3. Professor, Department of Pediatrics, Medical School, USP, São Paulo, SP, Brazil.

Financial support: FAPESP (Fundação de Amparo à Pesquisa no Estado de São Paulo).

Manuscript received Feb 11 2005, accepted for publication Jul 272005.

Suggested citation: Afiune JY, Singer JM, Leone CR. Echocardiographic post-neonatal progress of preterm neonates with patent ductus arteriosus. J Pediatr (Rio J). 2005;81:454-60. a little later, taking place in the majority of those with gestational ages of more than 30 weeks by 96 hours of life. ${ }^{2}$ In contrast, PT-NB with gestational ages less than 30 weeks and, in particular, those who exhibit hyaline membrane disease have an increased frequency of patent ductus arteriosus (PDA). 3,4 The ever greater use of exogenous surfactant has increased this incidence and has also seen a significant increase in left-right shunt through the ductus arteriosus. This being so, PDA can severely aggravate the clinical conditions of NB, increasing ventilation requirements and encouraging heart failure in addition to other consequences which together worsen the prognosis of PT-NB.

In recent years, innumerable studies have been undertaken with the objective of assessing the influence of PDA on the progress of PT-NB. Doppler echocardiogram with color flow mapping has become a fundamental tool for these assessments, allowing the early detection of this defect and 
also evaluation of its hemodynamic repercussions. It is clear that the global assessment of these repercussions should also be made based on clinical criteria as well, such as, for example, the presence of heart murmur, increased precordial activity or bounding pulses. Associations between clinical and echocardiographic parameters in a given group of PTNB can provide fundamental elements for the detection of PDA and also permits more appropriate treatment. 5,6

All of these factors lead us to postulate that the presence of PDA may cause echocardiographic alterations that would precede the clinical manifestations. The present study was therefore designed with the objective of analyzing the relationship between the echocardiographic findings in patent ductus arteriosus and the presence of clinical signs in PT-NB.

\section{Study population and methods}

This was a single center study of a longitudinal and prospective cohort, undertaken at the Nursery Annex at the Maternity Unit at the Hospital das Clínicas (FMUSP), part of the Pediatria Neonatal and Intensive Pediatric Service of the Instituto da Criança Professor Pedro de Alcântara at FMUSP.

The study population consisted of consecutive PT-NB with gestational ages of less than or equal to 34 weeks, born between 01 July 2000 and 03 August 2001. Informed consent was obtained from parents and the study was approved by the institution's Committee for Ethics in Research.

Infants were excluded if they exhibited a five minute Apgar score less than or equal to five or congenital heart disease (except patent foramen ovale or ductus arteriosus) or if they were the children of diabetic mothers.

The NB were classed according to birth weight as appropriate for gestational age (AGA) or small for gestational age (SGA). Newborns were defined as AGA if their birth weights were between the 10th and 90th percentiles of the intrauterine growth curves created by Ramos ${ }^{6}$ and SGA if their birth weights were below percentile 10 of the same reference standard. The definitive gestational age (GA) for each NB was determined based on the date of last menstruation or by the New Ballard method. ${ }^{7}$

The NB underwent clinical and echocardiographic examination on the third and seventh days of life and, then every week or 15 days, until reaching term, i.e., between the 38th and 40th weeks of postconceptional gestational age, or earlier if the patient was discharged or had died.

\section{Clinical evaluation}

The physical examination of the PT-NB was performed by a neonatologist, a member of the nursery's own treatment team, who was unaware of the echocardiogram results. The clinical variables investigated were: weight (grams); systemic arterial pressure in $\mathrm{mmHg}$, measured with an oscillometric, noninvasive method at the upper right arm, pulse pressure in $\mathrm{mmHg}$, defined as the difference between systolic and diastolic pressures; the presence of heart murmur or increased visible or palpable precordial activity. Clinical signs of PDA were defined as the presence of one or more of the following:

- heart murmur;

- pulse pressure above $30 \mathrm{mmHg}$;

- visibly increased precordial activity.

\section{Echocardiographic assessment}

The echocardiographic examinations were carried out using a TOSHIBA ${ }^{\circledR}$ SSH-140-A ultrasound machine with 5 and 7.5 MHz electronic sector transducer. All of the examinations were carried out at the bedside and the specialist operating the echocardiograph was unaware of the newborns' clinical status. Interobserver variation was eliminated by the use of a single examiner who was not involved in treating the NB (J.Y.A). Intraobserver variation was evaluated and did not exceed $4 \%$ of the echocardiographic measurements performed. All measurements were taken three times and averaged. An anatomic analysis was performed by sequential segmentation, defining the general cardiac anatomy and attempting to rule out all cardiac abnormalities. ${ }^{8}$

Echocardiographic measurements in $\mathrm{M}$ mode were taken in accordance with recommendations made by the American Society of Echocardiography, published in $1980^{9}$ and adapted for preterm newborn by Silverman in 1993.10 The following were evaluated: diameters of the aorta and left atrium and the left atrium-aorta ratio; systolic and diastolic diameters of the left ventricle; diastolic thickness of the interventricular septum and posterior left ventricle wall. By means of pulse Doppler, the aortic cardiac output in the left ventricle exit channel. ${ }^{11}$ The effects of PDA on each of these echocardiographic parameters was assessed.

The diameter of the ductus arteriosus was determined using color flow mapping, as described by Roberson \& Silverman. ${ }^{6}$ Ductus arteriosus diameter was defined as the smallest internal diameter observed by color flow mapping, closest to the pulmonary extremity of the ductus arteriosus.

Those NB with PDA on the third day of postnatal life were divided into two groups according to the postnatal evolution of their ductus arteriosus: Group A: NB who exhibited spontaneous ductus arteriosus closure by the seventh day of life and Group B: NB who had not exhibited spontaneous ductus arteriosus closure by the seventh day of life.

\section{Statistical analysis}

The patient sample was described using percentages, measures of central tendency (means) and of dispersal (standard deviation).

The effect that PDA had on the echocardiographic parameters investigated was gauged by means of the application of regression models, using techniques for the analysis of longitudinal data, using the presence/absence of PDA as co-variable. Significance was defined as a $p$ value of less than 0.05 . 
Student's t test was employed to compare the mean diameter of ductus arteriosus in group A with that in group B. Furthermore, a ROC curve was constructed with the objective of evaluating whether the diameter of the ductus arteriosus predicts its spontaneous closure and to identify cutoff points for differentiating these patients.

One possible association between the existence of clinical signs of PDA and failure to spontaneously close the ductus arteriosus was investigated by means of homogeneity tests (Pearson's chi-square). ${ }^{12}$

The statistical software package SPSS-10.0 was used for data analysis.

\section{Results}

Sixty-nine NB with GA at birth less than or equal to 34 weeks were selected for the study. Eight of them were excluded, four because their mothers had been given corticosteroids, three because they presented congenital heart disease (intraventricular communication in two and transposition of the great arteries in one) and the last due to severe perinatal asphyxia.

The characteristics of the newborn infants evaluated in this study are described in Table 1.

The clinical assessment performed on the third day of life detected heart murmur in eleven NB (18.0\%), visibly increased precordial activity in eight $(13.1 \%)$ and increased pulse pressure in just two NB (3.3\%). All of these NB had patent ductus arteriosus detected by echocardiographic examination.
On the third day of postnatal life PDA was detected in 21 NB (34.4\%). If the subset of NB with weights below 1,000 $\mathrm{g}$ is taken alone, PDA was observed in $58.8 \%$ (10/17), while among those weighing more than $1,000 \mathrm{~g}$, this incidence was $25 \%(11 / 44)$, which is a statistically significant difference $(p=0.0001)$. The presence of PDA was observed in $52.2 \%$ $(12 / 23)$ of those NB with GA of less than 30 weeks, while for the subset of NB with GA above 30 weeks, the incidence was $23.7 \%(9 / 38)$, which is also a statistically significant difference $(p<0.05)$.

The echocardiographic measurements were compared according to the presence or absence of PDA and investigate the difference between measurements for the two outcomes. It was observed that the presence of PDA significantly increased the diameter of the left atrium, diastolic and systolic left ventricle diameters, interventricular septum thickness and the posterior wall of the left ventricle in addition to aortic cardiac output measurements. The magnitudes of these increases for each variable are shown in Table 2 . The presence of PDA had no significant impact on the measurements of the aorta or the left atrium-aorta ratio.

Seven $(33.3 \%)$ of the 21 NB with PDA on the third day of life had exhibited spontaneous ductus arteriosus closure by the seventh day (Group A) and in 14 NB (66.6\%) this spontaneous closure did not take place (Group B). The mean diameter of the ductus arteriosus was significantly greater in group $B(2.6 \pm 0.7 \mathrm{~mm})$ than in group $A$ $(1.5 \pm 0.5 \mathrm{~mm} ; \mathrm{p}=0.003)$. The area under the ROC curve for no spontaneous ductus arteriosus closure was 0.93 $(95 \%$ IC $=0.81-1.04 ; p=0.003)$. The cutoff point that

Table 1 - Characteristics of preterm newborns assessed in the study

\begin{tabular}{lc}
\hline Characteristics of preterm NB & Number of NB assessed (61) \\
\hline Gestational age at birth (weeks) & $30 \pm 2(26-33)$ \\
Weight at term (g) & $1,211 \pm 210(740-1760)$ \\
Gender (male/female) & $30 / 31$ \\
Type of delivery (surgical/normal) & $34 / 27$ \\
Number of AGA/SGA NB & $29 / 32$ \\
Hyaline membrane disease (\%) & $34(56 \%)$ \\
Use of exogenous surfactant (\%) & $30(49 \%)$ \\
Mechanical Ventilation (\%) & $40(66 \%)$ \\
Deaths (\%) & $9(15 \%)$ \\
Number of NB according to gestational age at birth & 7 \\
$25-27$ weeks & 22 \\
$28-29$ weeks & 19 \\
$30-31$ weeks & 13 \\
$32-33$ weeks & \\
\hline
\end{tabular}

$\mathrm{NB}=$ newborns $; \mathrm{AGA}=$ apropriate for gestational age $; \mathrm{SGA}=$ small for gestational age . 
Table 2 - Effects of the presence of patent ductus arteriosus (PDA) on the echocardiographic examinations

\begin{tabular}{lcc}
\hline Echochardiographic examination variable & Effect of PDA presence & p \\
\hline Left atrium & $+0.61 \pm 0.27 \mathrm{~mm} / \mathrm{kg}$ & 0.03 \\
Diastolic left ventricle diameter & $+0.89 \pm 0.36 \mathrm{~mm} / \mathrm{kg}$ & 0.01 \\
Systolic left ventricle diameter & $+0.56 \pm 0.25 \mathrm{~mm} / \mathrm{kg}$ & 0.03 \\
Interventricular septum & $+0.20 \pm 0.07 \mathrm{~mm} / \mathrm{kg}$ & 0.01 \\
Posterior left ventricle wall & $+0.20 \pm 0.07 \mathrm{~mm} / \mathrm{kg}$ & 0.01 \\
Aortic cardiac output & $+40 \pm 10 \mathrm{ml} / \mathrm{kg} / \mathrm{min}$ & 0.0001 \\
Aorta & & $0.23(\mathrm{NS})$ \\
LA/AO relation & & $0.16(\mathrm{NS})$
\end{tabular}

$\mathrm{LA}=$ left atrium; $\mathrm{AO}=$ aorta; $\mathrm{NS}=$ non significant.

gave greatest sensitivity (100\%) for the identification of NB with no spontaneous closure was a $1.7 \mathrm{~mm}$ diameter ductus arteriosus. The point that gave the greatest specificity $(100 \%)$ was at $2 \mathrm{~mm}$ diameter.

With respect of clinical signs of PDA (heart murmur, increased precordial activity or increased pulse pressure) on the third day of postnatal life, a significantly greater frequency was observed for group B (71.4\%) than for group A (14.3\%; $p=0.013$ ) (Table 3).

None of the NB in group A exhibited reopened ductus arteriosus during the follow-up period. Ten of the NB in group $B$ received pharmacological treatment with indomethacin, one NB underwent surgery, and the remaining three NB suffered fatal outcomes on the fourth day of life without having received treatment for ductus arteriosus.

Pharmacological treatment for ductus arteriosus was given by the 14th day of postnatal, with three doses of indomethacin $(0.2 \mathrm{mg} / \mathrm{kg} /$ dose given enterally) given at 12 hour intervals. Eight ( $80 \%$ ) of these NB exhibited complete ductal closure and none of them exhibited reopened ductus arteriosus during the follow-up period. Two NB (20\%) exhibited partial closure after 1 cycle of indomethacin, one of whom was given a second cycle, resulting in complete closure. In one case the decision was taken to treat the ductus arteriosus with surgery on the fifth day of postnatal

Table 3 - Characteristics of preterm newborns that had spontaneous closure of the arterial canal (group A) versus those with no spontaneous closure (group B)

\begin{tabular}{lccc}
\hline & $\begin{array}{c}\text { Group A } \\
\mathbf{7}(\mathbf{3 3 . 3} \%)\end{array}$ & $\begin{array}{c}\text { Group B } \\
\mathbf{1 4}(\mathbf{6 6 . 6 \% )}\end{array}$ & p \\
\hline Gestational age (weeks) & $29.8 \pm 2.1$ & $28.7 \pm 2.3$ & $\mathrm{NS}$ \\
Weight (g) & $1011 \pm 284$ & $1092 \pm 266$ & $\mathrm{NS}$ \\
Hyaline membrane disease & $7(100 \%)$ & $12(86 \%)$ & $\mathrm{NS}$ \\
Use of surfactant & $4(57 \%)$ & $12(86 \%)$ & $\mathrm{NS}$ \\
Mechanical ventilation & $7(100 \%)$ & $13(93 \%)$ & $\mathrm{NS}$ \\
Diameter of the arterial channel (mm) & $1.4 \pm 0.6$ & $2.6 \pm 0.6$ & $\mathrm{p}=0.003$ \\
Presence of clinical signals & $1(14.3 \%)$ & $10(71.4 \%)$ & $\mathrm{p}=0.013$ \\
\hline
\end{tabular}

NS = non significant. 
life, since pharmacological treatment was not attempted because of gastric hemorrhaging.

The three NB who presented PDA on day three and went on to die on the fourth, suffered massive pulmonary hemorrhaging. These NB had GA below 30 weeks, diagnoses of hyaline membrane disease, were given exogenous surfactant on the first day of life and all had a ductus arteriosus with a diameter of more than $2 \mathrm{~mm}$. However, none of them had presented clinical signs of PDA on the third day of life.

\section{Discussion}

The behavior of PDA in PT-NB has been the subject of innumerable studies for almost 30 years. ${ }^{13-17}$ There are, however, few in the published literature that have prospectively assessed the behavior of PDA in PT-NB, correlating clinical data with findings from echocardiography with Doppler and color flow mapping. ${ }^{6}$

In this study we observed a $34.4 \%$ incidence of PDA on the third day of life. This incidence was significantly higher among NB with birth weights below $1,000 \mathrm{~g}$ (58.8\%) and also among those with GA at birth of less than 30 weeks $(52.2 \%)$. These results are comparable with findings by Reller et al. ${ }^{2}$ who reported an incidence of PDA, on the third day of postnatal life, of around $50 \%$ of NB with GA at birth of less than 29 weeks, and an even higher incidence among those with hyaline membrane disease (77\%).

One of the most intriguing issues in the evolution of PDA in PT-NB is the definition of the hemodynamic repercussions of ductus arteriosus, which sometimes is not easy in clinical practice, as was described by Evans ${ }^{18}$ This is why the association with echocardiographic assessment is of fundamental importance. In this study, the effect of PDA was assessed in relation to certain echocardiographic variables. It was observed that ductus arteriosus significantly increased systolic and diastolic left ventricle diameters, left atrium diameter, interventricular septum and wall thickness and aortic cardiac output. These results demonstrate a dilatation of the left-hand cardiac chambers, probably as a result of excessive pulmonary flow and increased pulmonary venous return to the left atrium. In this state left ventricular systolic volume is increased and, finally, so is aortic cardiac output. It was observed that the increase in cardiac output in the presence of PDA reached approximately $40 \mathrm{ml} / \mathrm{min} / \mathrm{kg}( \pm 10 \mathrm{ml} / \mathrm{min} / \mathrm{kg})$, which accounts for a mean increase on these NB's baseline cardiac output of $30 \%$. This result is in agreement with others in the literature, such as findings described by Walther et al., who observed an increase in the aortic cardiac output of NB with birth weights below $1,250 \mathrm{~g}$ of around $60 \mathrm{ml} / \mathrm{min} / \mathrm{kg}$, in the presence of ductus arteriosus and with hemodynamic repercussions. ${ }^{19}$ Lindner et al. observed an increase in aortic cardiac output of up to $50 \%$ against baseline and also observed that, after ductal closure, the cardiac output level returned to baseline. ${ }^{11}$
One measurement that has always been much used in the literature top assess the repercussions of ductus arteriosus is the left atrium/aorta ratio, with a ratio of more than 1.5 exhibiting high sensitivity and specificity for detecting ductus arteriosus, as reported by Iyer \& Evans. ${ }^{20}$ In this study, however, we did not observe any effect of PDA on this echocardiographic measurement, with no significant difference demonstrated. This might be because in many PT-NB, the size of the aorta is already enlarged and, even if the left atrium also increases, the $\mathrm{LA} / \mathrm{AO}$ ratio may not. Another motive may be the presence of a patent foramen ovale, which may reduce the size of the left atrium, by left-right interatrial shunting, even in the presence of a large ductus arteriosus. ${ }^{21}$

With relation to clinical diagnosis of PDA, we observed that clinical symptoms were present in $52 \%$ of the NB with PDA on the third day of life, which is compatible with the literature, with heart murmur being the most common clinical symptom. In other studies a hyperactive precordium has been the most sensitive clinical sign for PDA diagnosis, attaining a sensitivity of $95 \%$, as reported by Kupferschmid et al. ${ }^{22}$ However, their clinical assessment was performed at the end of the first week of postnatal life, in contrast with our study, in which assessments were made on day three. This could explain the differences in the two studies' observations since on the third day it is possible that a hyperactive precordium may not yet be detectable.

It is known that when PDA is diagnosed on the third day of life there is always the possibility of its spontaneous closure. In their study, Roberson \& Silverman found an incidence of spontaneous ductal closure after day three of $27.1 \%$ of the NB studied. ${ }^{6}$ That result is similar to our study, in which spontaneous closure of the ductus arteriosus took place in $33.3 \%$ of the NB studied.

This study employed a sample of convenience that consecutively included all patients during the study period. Taking into account the sample size (seven patients in group $A$ and 14 in group B) and the mean diameter of $1.4 \pm 0.5 \mathrm{~mm},{ }^{6}$ for the ductus arteriosus in the general population, this study offered a power of $80 \%$ with alpha at $5 \%$ for the detection of a difference of $60 \%$ between study groups, which, in our opinion, is satisfactory, although it remains a weak point of the study.

When a comparative analysis was performed of the subset of NB who exhibited spontaneous ductal closure (group A) against the group in which this did not occur (group B), it was observed that the two groups were comparable in terms of birth weight, gestational age at birth, incidence of hyaline membrane disease, use of surfactant and need for mechanical ventilation. It was also observed, however, that ductus arteriosus diameter was larger in group $B(2.6 \pm 0.6 \mathrm{~mm})$ than group $A(1.4 \pm 0.6 \mathrm{~mm})$, which is similar to results observed by Roberson \& Silverman, who reported ductus arteriosus measurements of $2.6 \pm 0.7$ $\mathrm{mm}$ and $1.8 \pm 0.8 \mathrm{~mm}$, respectively. ${ }^{6}$

These results demonstrate that the larger the duct, the lower the chance of spontaneous closure. So, from what size 
of diameter onwards does closure fail to occur? In an attempt to answer this question we constructed a ROC curve on which we could observe that the cutoff point for duct diameter with greatest sensitivity (100\%) was $1.7 \mathrm{~mm}$ and the diameter with greatest specificity $(100 \%)$ was $2.2 \mathrm{~mm}$. In other words we can state that PDA smaller than $1.7 \mathrm{~mm}$ will probably close spontaneously, while those above 2.2 $\mathrm{mm}$ will not close spontaneously. In a similar study of PTNB under 1,500 g, Kluckow \& Evans found that an internal ductus arteriosus diameter above $1.5 \mathrm{~mm}$ offered a sensitivity of $81 \%$ and specificity of $85 \%$ for detecting PDA with hemodynamic repercussions. ${ }^{23}$

Pharmacological treatment of the ductus arteriosus was given to 10 patients in group B with indomethacin given enterally. This is because when the study was carried out, intravenous indomethacin was not available at the hospital where this study was performed. Even so, treatment was successful for eight of these patients ( $80 \%)$.

Clinical signs of PDA were observed on the third day of life in just $14.3 \%$ of the group in which there was spontaneous ductal closure and in $71.4 \%$ of the other group, which is also similar to results described by Roberson \& Silverman. ${ }^{6}$ This demonstrates that the presence of clinical signs on day three should increase the risk of failure to close spontaneously.

It is well worth emphasizing that, in our study, three NB with GA of less than 30 weeks and who presented PDA diameters greater than $2.2 \mathrm{~mm}$, but with no clinical signs on day three, suffered fulminating deterioration with severe pulmonary hemorrhaging and death between the third and fourth days of life, with no specific treatment for ductus arteriosus having been attempted. This would appear to be a special group of NB, who present a high risk of developing severe and fatal complications, possibly due to the major left-right flow through the ductus arteriosus which targets the lungs in the first instance.

As a result of this, it becomes ever more necessary to attempt to identify this group of NB as early as possible so that more aggressive treatment can be employed, even before the third day of life. Some international perinatology centers have observed that, in NB with birth weights below $1,000 \mathrm{~g}$ who present PDA on the first day of life, there is an $80 \%$ risk of developing persistent signs of ductus arteriosus. 24 In a prospective, randomized study carried out by Couser et al., indomethacin was used prophylactically during the first 24 hours of the lives of PT-NB who had received surfactant in the delivery room, observing a significant reduction in left-right shunt via the ductus arteriosus. ${ }^{25}$

In conclusions, we can state that among PT-NB, and especially among those with GA less than 30 weeks, the observation on the third day of life of a persistent patent ductus arteriosus with a diameter of more than $2.2 \mathrm{~mm}$ on echocardiogram with color flow mapping can predict the need for treatment, especially when there is also at least one clinical sign. Such NB should be given pharmacological or surgical treatment to close the ductus arteriosus as quickly as possible.

\section{References}

1. Gentile R, Stevenson GM, Dooley T, Franklin D, Kawabori I, Pearlman A. Pulsed Doppler echocardiographic determination of time of ductal closure in normal newborn infants. J Pediatr. 1981;98:443-8.

2. Reller MD, Rice MJ, McDonald RW. Review of studies evaluating ductal patency in the premature infant. J Pediatr. 1993;122: S59-62.

3. Dudell GG, Gersony WM. Patent ductus arteriosus in neonates with severe respiratory disease. J Pediatr. 1984;104:915-20.

4. Hammerman C, Strates C, Valaitis S. The silent ductus: its precursors and its aftermath. Pediatr Cardiol. 1986;7:121-7.

5. Ellison R, Peckham G, Lang P. Evaluation of the preterm infant for patent ductus arteriosus. Pediatrics. 1983;71:364-72.

6. Roberson DA, Silverman NH. Color Doppler flow mapping of the ductus arteriosus in very low birthweight neonates: echocardiographic and clinical findings. Pediatr Cardiol. 1994;15:219-24.

7. Ballard JL, Novalli KL, Driver M. A simplified score for assessment of fetal maturation of newly born infants. J. Pediatr. 1979;95: 769-74.

8. Anderson RH, Becker AE, Freedom RM, Macartney FJ, QueroJimenez M, Shinebourne EA, et al. Sequential segmental analysis of congenital heart disease. Pediatr Cardiol. 1984;5:281-8.

9. Henry WA, Gardin JM, Ware J. Echocardiographic measurements in normal subjects from infancy to old age. Circulation. 1980;62:1054-61.

10. Silverman N. Quantitative methods to enhance morphological information using $\mathrm{M}$-mode, Doppler and cross sectional ultrasound. In: Silverman N, editor. Paediatric echocardiography. 1st ed. London: Williams and Wilkins; 1993. p. 35-6.

11. Lindner W, Seidel M, Versmold H T. Stroke volume and left ventricular output in preterm infants with patent ductus arteriosus. Pediatr Res. 1990;27:278-81.

12. Agresti A. Categorical data analysis. 2nd ed. New York: Wiley; 1990.

13. Silverman NH, Lewis AB, Heymann MA, Rudolph AM. Echocardiographic assessment of ductus arteriosus shunt in premature infants. Circulation. 1974;50:821-5.

14. Heymann MA, Rudolph AM. Control of the ductus arteriosus. Physiol Rev. 1975;55:62-78.

15. Serwer GA, Armstrong BE, Anderson PAW. Continuous wave Doppler ultrasonographic quantification of patent ductus arteriosus flow. J Pediatr. 1982;100:297-9.

16. Swensson RE, Valdez-Cruz LM, Sahn DJ, Sherman FS, Chung KJ, Scagnelli S, et al. Real-time Doppler color flow mapping for detection of patent ductus arteriosus. J Am Coll Cardiol. 1986;8:1105-12.

17. Kappa $P$, Seppanen $M$, Kero $P$, Saraste $M$. Pulmonary hemodynamics after synthetic surfactant replacement in neonatal respiratory distress syndrome. J Pediatr. 1993;123:115-9.

18. Evans N. Diagnosis of patent ductus arteriosus in the preterm newborn. Arch Dis Child. 1993;68:58-61.

19. Walther FJ, Kim DH, Ebrahimi M, Siassi B. Pulsed Doppler measurement of left ventricular output as early predictor of symptomatic patent ductus arteriosus in very preterm infants. Biol Neonate. 1989;56:121-8.

20. Iyer P, Evans N. Re-evaluation of the left atrial to aortic root as a marker of patent ductus arteriosus. Arch Dis Child Fetal Neonatal. 1994;70:112-7.

21. Evans N, Iyer P. Assessment of ductus arteriosus shunt in preterm infants supported by mechanical ventilation: effect of interatrial shunting. J Pediatr. 1994;125:778-85.

22. Kupferschmid C, Lang D, Pohlandt F. Sensitivity, specificity and predictive value of clinical findings, M-mode echocardiography and continuous wave Doppler sonography in the diagnosis of symptomatic patent ductus arteriosus in preterm infants. Eur ] Pediatr. 1988;147:279-82.

23. Kluckow M, Evans N. Early echocardiographic prediction of symptomatic patent ductus arteriosus in preterm infants undergoing mechanical ventilation. J Pediatr. 1995;127:774-9. 
24. Mahony L, Caldwell RL, Girod DA. Indomethacin therapy on the first day of life in infants with very low birth weight. J Pediatr. 1985; 106:801-5.

25. Couser RJ, Ferrara TB, Wright GB, Cabalka AK, Schilling CG, Hoekstra RE, et al. Prophylactic indomethacin therapy in the first twenty-four hours of life for the prevention of patent ductus arteriosus in the preterm infants treated prophylactically with surfactant in the delivery room. J Pediatr. 1996;128:631-7.
Correspondence:

Jorge Yussef Afiune

SQSW 102, bloco D, Apto. 605

CEP 70670-204 - Cruzeiro Novo, DF, Brazil

Tel.: + 55 (61) 3403.5508

Fax: +55 (61) 3405.5435

E-mail: jorge.afiune@incordf.zerbini.org.br 